\title{
Effect of annealing atmosphere on structural and optical properties of CZTS thin films prepared by spin-coating
}

\author{
S. Akhanda ${ }^{1 *}$, R. Matin ${ }^{2}$, M. S. Bashar ${ }^{2}$, M. Sultana ${ }^{2}$, A. Kowsar ${ }^{3}$, M. Rahaman' ${ }^{2}$ and Z. H. Mahmood ${ }^{1}$ \\ ${ }^{1}$ Department of Electrical and Electronic Engineering, University of Dhaka, Dhaka, Bangladesh \\ ${ }^{2}$ Institute of Fuel Research and Development (IFRD), Bangladesh Council of Scientific and Industrial Research (BCSIR), \\ Dhaka, Bangladesh \\ ${ }^{3}$ BCSIR Laboratories, Rajshahi, Bangladesh
}

\begin{abstract}
Copper zinc tin sulfide (CZTS) thin films were deposited by spin coating procedure of a sol-gel prepared from the solution of copper (II)chloride, zinc acetate, tin (II) chloride and thiourea in 2-methoxyehtanol followed by annealing under two different atmospheres viz. $\mathrm{N}_{2}$ gas and Sulphur (S) powder at $530{ }^{\circ} \mathrm{C}$ for 5 minutes. The effect of different annealing atmosphere on the structural and optical properties of the CZTS thin films were investigated. The X-ray diffraction study showed higher intensity peaks for films annealed under $\mathrm{N}_{2}$ gas ambient. SEM study revealed that the surfaces of the films in both cases are non-uniform. Films annealed in $\mathrm{N}_{2}$ gas atmosphere showed better absorption coefficient (exceeding $10^{4} \mathrm{~cm}^{-1}$ in the visible region) than the sulphurized ones. The optical band gap ( $\mathrm{E}_{\mathrm{g}}$ ) of the films were found to be in the range of $1.46-1.53 \mathrm{eV}$.
\end{abstract}

Keywords: CZTS thin-film; Spin coating; X-ray diffraction; Scanning electron microscope; UV-visible spectrometry

\section{Introduction}

Emerging $\mathrm{Cu}_{2} \mathrm{ZnSnS}_{4}$ (CZTS) based solar cell has drawn the attention of the researchers due its earth-abundant low cost non-toxic raw materials and it is considered to bethe best replacement of the conventional CIGS thin-film solar cell which has rare earth constituent Indium (In) and highly expensive Gallium (Ga)in its composition (Siebentritt, 2013). Copper zinc tin sulfide thin filmplays the vital role of capturing sunlight and converting it into electricity. Structural, optical and electrical properties of this layer have a profound impact on the overall performance of the solar cell. To date, a list of deposition techniques has been applied to deposit this CZTS thin film. Among these, the high vacuum techniques used are pulse laser deposition (Agawane et al., 2014), co-evaporation (Tanaka et al., 2006), sputtering (Wang et al., 2013; Zhou et al., 2013). Non-vacuum process includes spray pyrolysis (Valdes et al., 2014), electro-deposition (Li et al., 2015), spin coating (Kahraman et al., 2013), successive ionic layer adsorption and reaction (Suryawanshi et al., 2014), and chemical bath deposition (Wangperawong et al., 2011). Of these techniques, spin coating is frequently used to deposit CZTS absorber layer because of its simplicity for having less steps and also its ability to produce a uniform stable thin film (Kahraman et al., 2013). The precursor solution used in majority of them is sol-gel. Sol-gel prepared spin coated thin-film also subjected to annealing chamber for robust and physically stable film where it experiences different types of inert atmosphere such $\mathrm{H}_{2} \mathrm{~S}$ (Min et al., 2009), $\mathrm{N}_{2}$ gas (Jiang et al., 2014; Jiang et al., 2011) and $\mathrm{S}$ powder (Su et al., 2014). But using $\mathrm{H}_{2} \mathrm{~S}$ gas in annealing chamber creates toxic hazard atmosphere (Min et al., 2009).

In this study, CZTS absorber layer has been prepared through a sol-gel spin coating process followed by annealing in two different atmospheres ( $\mathrm{N}_{2}$ gas annealed and sulphurized) and the effect of these two different annealing conditions on their structural, morphological and optical properties were studied.

\section{Materials and methods}

$\mathrm{Cu}_{2} \mathrm{ZnSnS}_{4}$ thin films were deposited on soda lime glasses by spin-coating method. The chemicalsused were copper (II) chloride (2.05 M) (VWR international, England, 99\%), zinc acetate (1.13 M) (Scharlu, Spain, 99\%), tin (II) chloride $(0.75 \mathrm{M})$ (Scharlu, Spain, 99\%) and thiourea $(16.28 \mathrm{M})$ (Merck, Germany, 99\%) in 2-methoxyehtanol $(10 \mathrm{ml})$ (Merck, Germany, 98\%). At first, the solutions of metal saltwere mixed at room temperature. A magnetic stirrer bar was placed inside the beaker for uniform mixing. Then the solution temperature was gradually increased. When the temperature reached at $45^{\circ} \mathrm{C}$, thiourea was added to the 
solution and after that the temperature was again increased and fixed at $60^{\circ} \mathrm{C}$. Two drops $(\sim 5 \mu \mathrm{L})$ of mono ethanol amine (MEA) was added to the solution as stabilizer. Then the solution was stirred for 90 minutes and gradually the colorless transparent solution turned into a transparent yellow sol-gel over time. Then it was aged for more than 18 hours at room temperature before being used in the spin coating process. A further stirring of the solution was done at $55^{\circ} \mathrm{C}$ for 20 minutes before spin coating. Spin coating was done in a two-step process. In the first step, the spin coating was performed at 600 rotations per minute (rpm) for 10 seconds. In the second step, the spin coating was done at $1800 \mathrm{rpm}$ for 20 seconds. Then the films were dried at $250{ }^{\circ} \mathrm{C}$ but, the time duration used was different for each film sample. This whole coating process was repeated three times for the films to obtain desirable thickness. To realize the effect of annealing atmosphere i.e., the effect of $\mathrm{N}_{2}$ gas and $\mathrm{S}$ powder in annealing chamber, on structural and optical properties of sol-gel spin coated CZTS thin films, two sets of films were annealed at $530{ }^{\circ} \mathrm{C}$ (temperature ramp: $10^{\circ} \mathrm{C}$ per minute) for 5 minutes separately. Films were wrapped in aluminum foil with $\mathrm{S}$ powder inside for the annealing in $\mathrm{S}$ powder atmosphere. Films annealed in $\mathrm{N}_{2}$ gas atmosphere were labeled as Sample 1,2 and 3 with respect to their pre-annealing time of 60,90 and 120 seconds respectively. Other films annealed in $\mathrm{S}$ powder at $530{ }^{\circ} \mathrm{C}$ for 5 minutes were labeled as Sample 4, 5 and 6 respectively with respect to their pre-annealing time of 60, 90 and 120 seconds respectively. Oven (Binder, USA) was used for the pre-annealing purpose. Table I illustrates the whole procedure in detail.

Table I. CZTS Deposition and process conditions used in this work

\begin{tabular}{|c|c|c|c|c|}
\hline Chemicals & $\begin{array}{c}\text { Pre-annealing } \\
\text { temperature }\left({ }^{\circ} \mathrm{C}\right)\end{array}$ & $\begin{array}{l}\text { Pre -annealing } \\
\text { time (seconds) }\end{array}$ & $\begin{array}{l}\text { Annealing } \\
\text { conditions }\end{array}$ & Label \\
\hline $\mathrm{CuCl}_{2} .2 \mathrm{H}_{2} \mathrm{O}-2.0545 \mathrm{M}$ & & 60 & \multirow{6}{*}{$\begin{array}{l}\text { In } \mathrm{N}_{2} \text { gas at } \\
530^{\circ} \mathrm{C} \text { for } 5 \\
\text { minutes }\end{array}$} & Sample 1 \\
\hline $\mathrm{Zn}\left(\mathrm{CH}_{3} \mathrm{COO}\right)_{2} .2 \mathrm{H}_{2} \mathrm{O}-1.13 \mathrm{M}$ & & 90 & & Sample 2 \\
\hline $\mathrm{SnCL}_{2} .2 \mathrm{H}_{2} \mathrm{O}-0.75 \mathrm{M}$ & & 120 & & Sample 3 \\
\hline \multirow[t]{3}{*}{$\mathrm{NH}_{2}-\mathrm{CS}-\mathrm{NH}_{2}-16.28 \mathrm{M}$} & \multirow[t]{3}{*}{250} & 60 & & Sample 4 \\
\hline & & 90 & & Sample 5 \\
\hline & & 120 & & Sample 6 \\
\hline
\end{tabular}

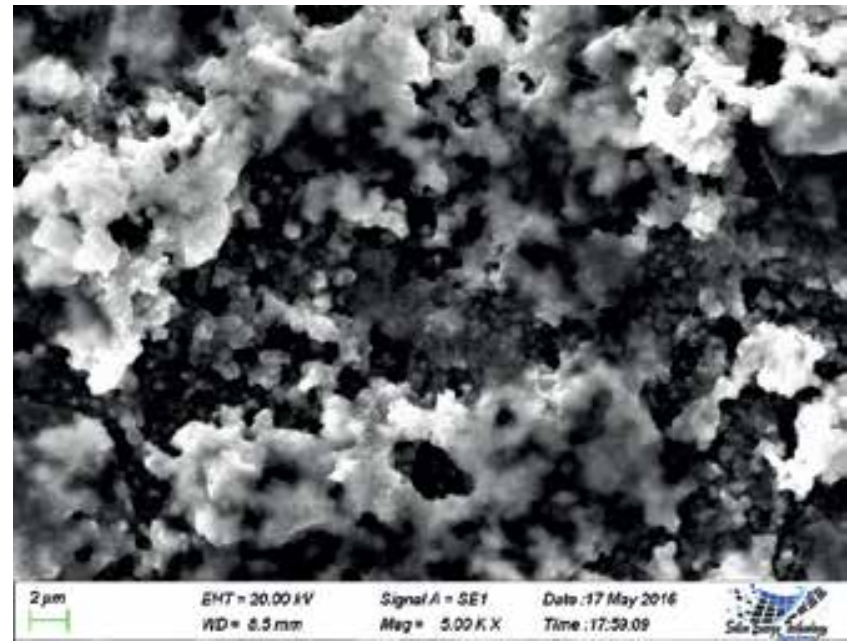

Fig. 1. SEM micrograph of $\mathrm{N}_{2}$ gas annealed CZTS thin film

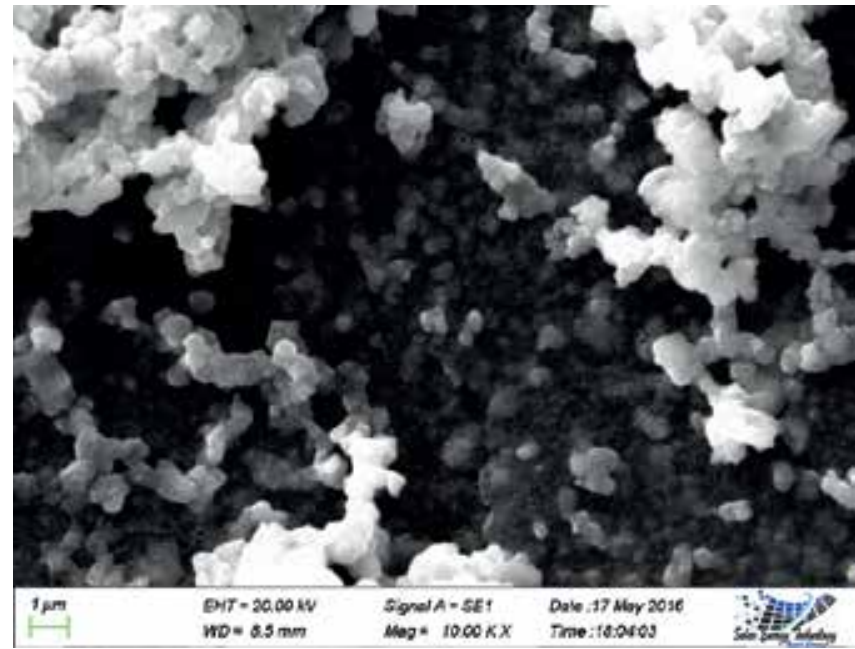

Fig. 2. SEM micrograph of sulphurized CZTS thin film 
BRUKER D8 X-ray Diffractometer was used for the crystalline phase identification. The surface morphology of the as-deposited and annealed films was investigated by a 6490 JEOL JSM model scanning electron microscope (SEM). The optical parameters were estimated from data obtained using a UH4150 Spectrophotometer in the $300-$ $900 \mathrm{~nm}$ wavelength range.

\section{Results and discussion}

Fig. 1 and Fig. 2 show the SEM micrograph of the surface of the $\mathrm{N}_{2}$ gas annealed and sulphurized CZTS thin films respectively. Both the images confirm that the surface is coarse, large agglomeration of grains covered with clusters and consist few voids. This has occurred due to volume contraction arising from the evaporation of volatile products in CZTS precursor (Park et al., 2013) (Suryawanshi et al., 2014).

Fig. 3 and Fig. 4 show the EDAX spectrum of the $\mathrm{N}_{2}$ gas annealed and sulphurized CZTS thin films respectively. Table II shows the atomic percentage of different elements present in the films under two different annealing conditions that closely matches the $\mathrm{Cu}_{2} \mathrm{ZnSnS}_{4}(\mathrm{CZTS}):: \quad 2: \quad 1: 1: 4$ compositional ratios. It is evident from the table that in both cases the films are $\mathrm{Cu}$-rich and $\mathrm{Zn}$-poor. But, sulphurization results in making the film even more $\mathrm{Cu}$-rich and $\mathrm{Zn}$-poor.

Normalized XRD pattern of all $\mathrm{N}_{2}$ gas annealed film (Fig. 5) shows reflection peaks corresponding to the (112), (220), (312) planes of reflection. These are the characteristic peaks of the kesterite structure according to JCPDS no: 26-0575. Though the films were pre-annealed for 60, 90 and 120 seconds, all three XRD patterns were almost identical in their peak intensity. This suggests that the pre-annealing temperature did not affect the crystallinity of these three films. The normalized XRD pattern of the films labeled as 'Sample 5' and 'Sample 6' in Fig. 6 also show peaks corresponding to the (112), (220), (312) planes of reflection. These two films were pre-annealed for 90 and 120 seconds respectively. Film pre-annealed for 60 seconds at $250{ }^{\circ} \mathrm{C}$ (Sample 4) did not show any characteristic peak. There is only abroad peak around 25 degrees in the XRD pattern (Fig. $6)$. This confirms the poly crystalline nature of this film. For the other two films (Fig. 6) an increase in pre-annealing time results in increased magnitude of the CZTS characteristic peaks. From this we can say that the sulphurized films' crystallinity improves with increasing pre-annealing time. The highest intensity of the characteristic peaks of the

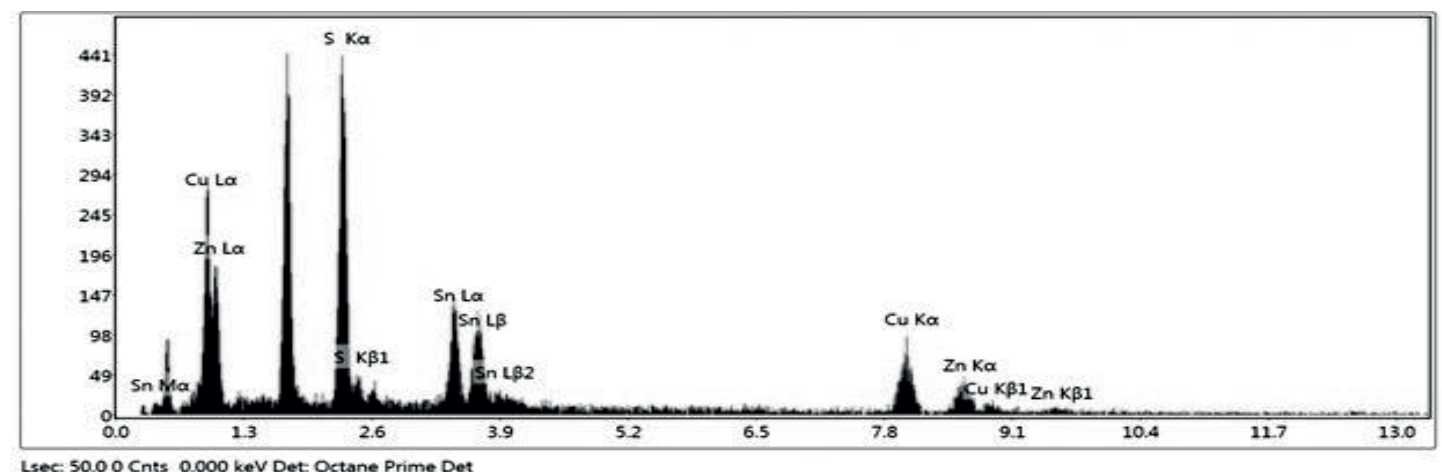

Fig. 3. EDAX spectrum of $\mathbf{N}_{2}$ gas annealed film (Sample 2)

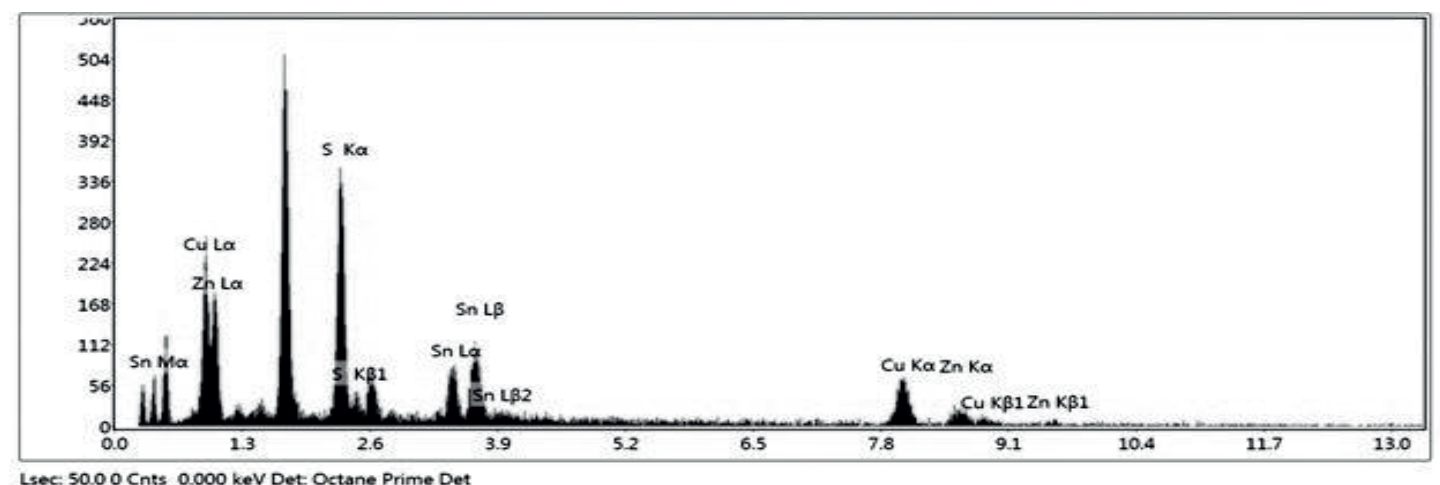

Fig. 4. EDAX spectrum of sulphurized film (Sample 5) 
sulphurized film is less than that of any of the films that were annealed in presence of $\mathrm{N}_{2}$ gas. From this it can be said that, CZTS films annealed in $\mathrm{N}_{2}$ gas atmosphere has bigger crystallite size. Distinction between CZTS phase and secondary phases like $\mathrm{Cu}_{\mathrm{x}} \mathrm{S}$, cubic $\mathrm{ZnS}$ and tetragonal $\mathrm{Cu}_{2} \mathrm{SnS}_{3}$ could not be made from the XRD pattern because of the closeness of their peak intensity positions. Raman study should be carried out for this purpose.

CZTS is a very promising material for the absorber layer of a solar cell because of its strong absorption over a broad solar spectrum. The direct optical band gaps $\left(\mathrm{E}_{\mathrm{g}}\right)$ of the CZTS

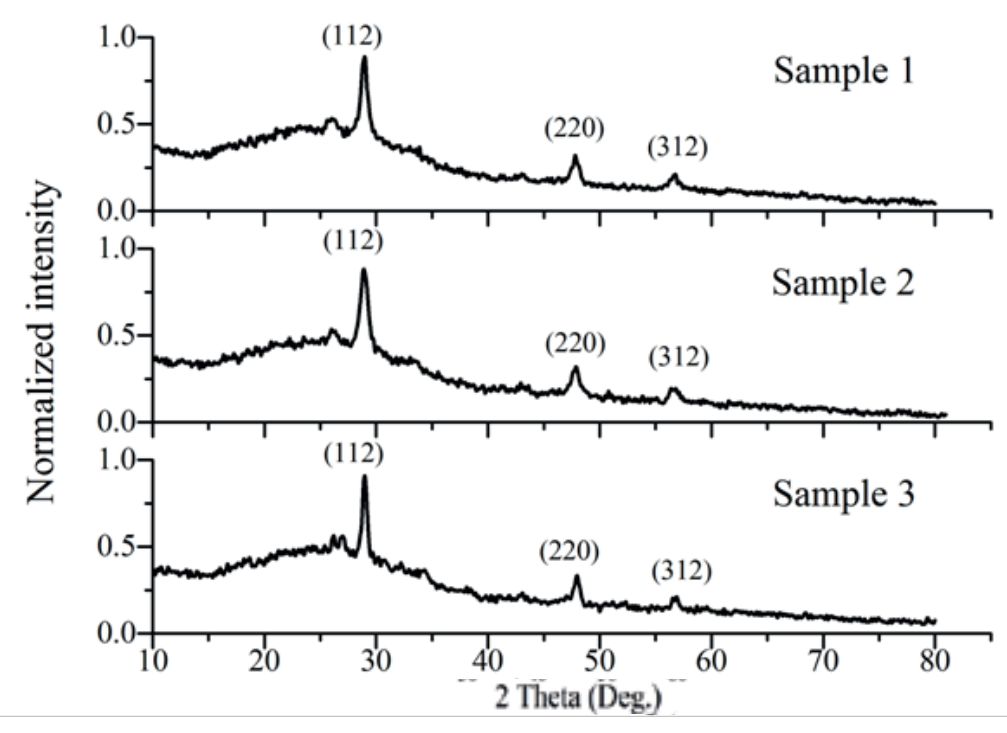

Fig. 5. XRD (vertically off-set) of $\mathbf{N} 2$ gas annealed CZTS thin films

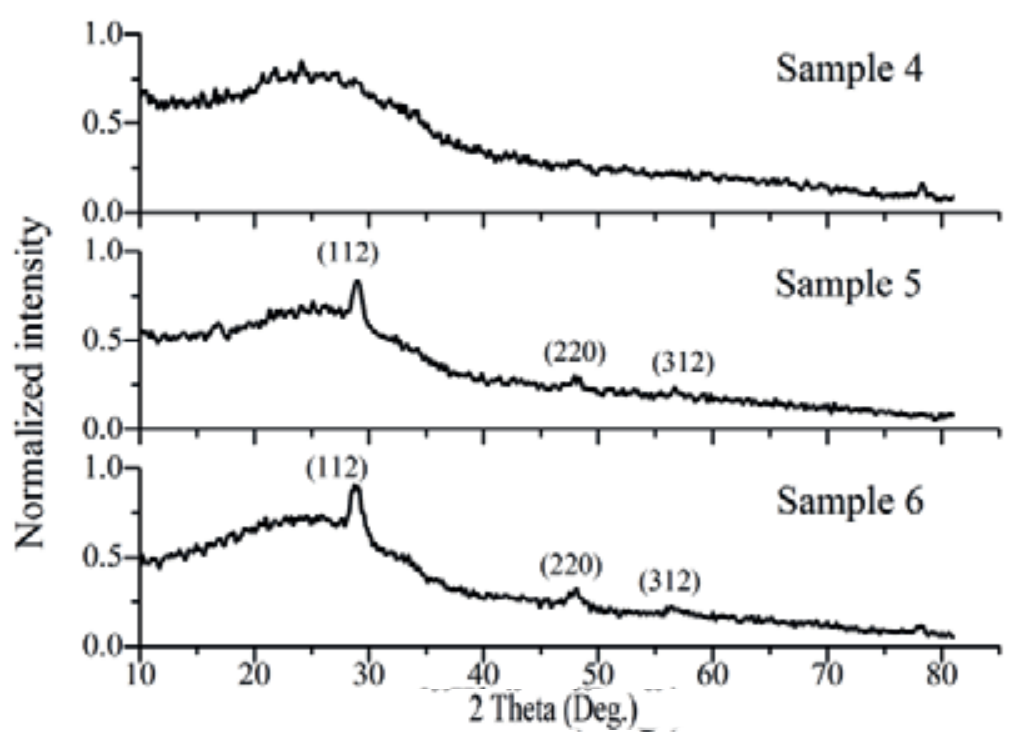

Fig. 6. XRD (vertically off-set) of sulphurized CZTS thin films 
Table II. Elemental composition of the CZTS thin films from EDAX analysis

\begin{tabular}{ccc}
\hline Element & \multicolumn{2}{c}{ Atomic Percentage (\%) } \\
\cline { 2 - 3 } & $\mathrm{N}_{2}$ gas anneale d films & Sulphurized films \\
(pre -annealing time $=90$ second) & (pre -annealing time $=90$ second) \\
\hline $\mathrm{Cu} \mathrm{K}$ & 25.9 & 29.2 \\
\hline $\mathrm{Zn} \mathrm{K}$ & 16.9 & 13.5 \\
\hline $\mathrm{Sn} \mathrm{L}$ & 11.5 & 4.8 \\
\hline $\mathrm{S} \mathrm{K}$ & 45.7 & 48.5
\end{tabular}

thin films were determined from Tauc plot and found to be in the range of 1.46-1.53 eV (Fig. 7 and Fig. 8). Tauc plots were obtained from the absorbance spectra measured by the UV-vis spectrometry in the wavelength range of 300-900 $\mathrm{nm}$.

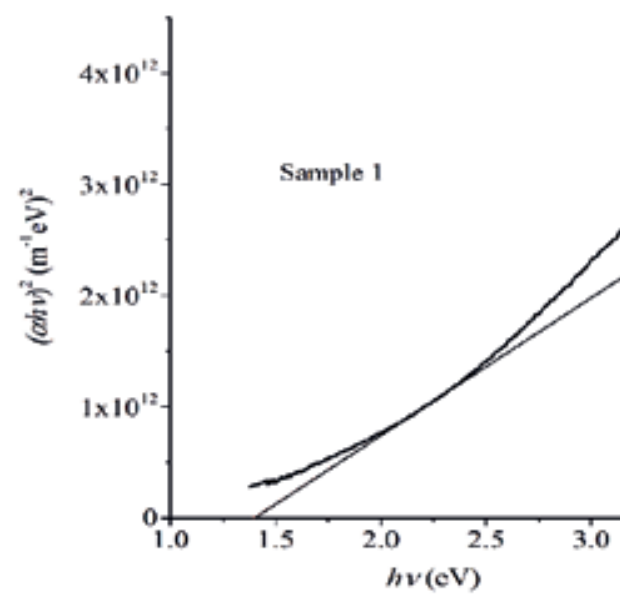

Fig. 7(a). Tauc plot-Sample 1

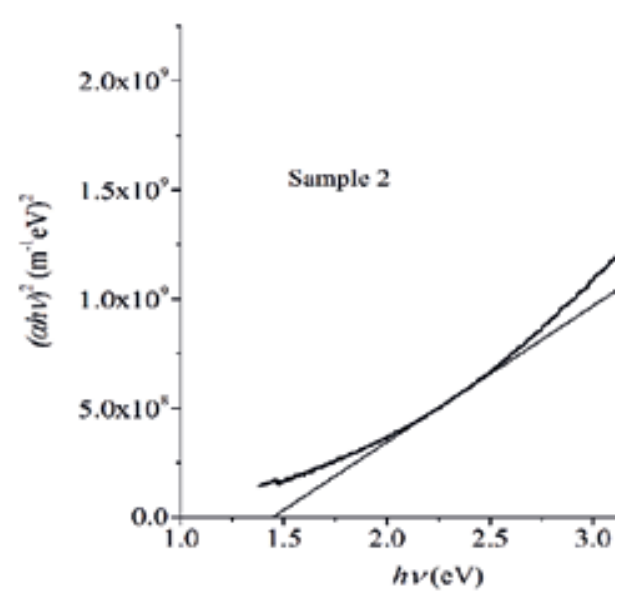

Fig. 7(b). Tauc plot-Sample 2
The optical absorption coefficients calculated is shown in Figs. 9 and Fig. 10.

It is found to be greater than $10^{4} \mathrm{~cm}^{-1}$ for 'Sample 2' and 'Sample 3' (Fig. 9). These optical parameters are well suited for the absorber layer of a solar cell.

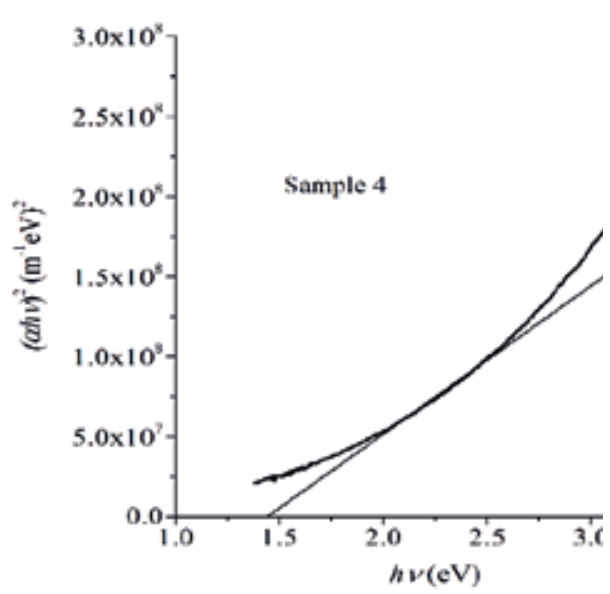

Fig. 8(a). Tauc plot-Sample 4

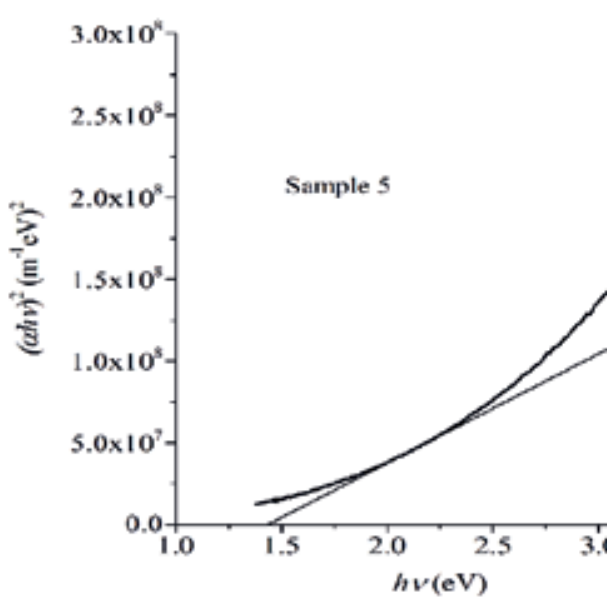

Fig. 8(b). Tauc plot-Sample 5 


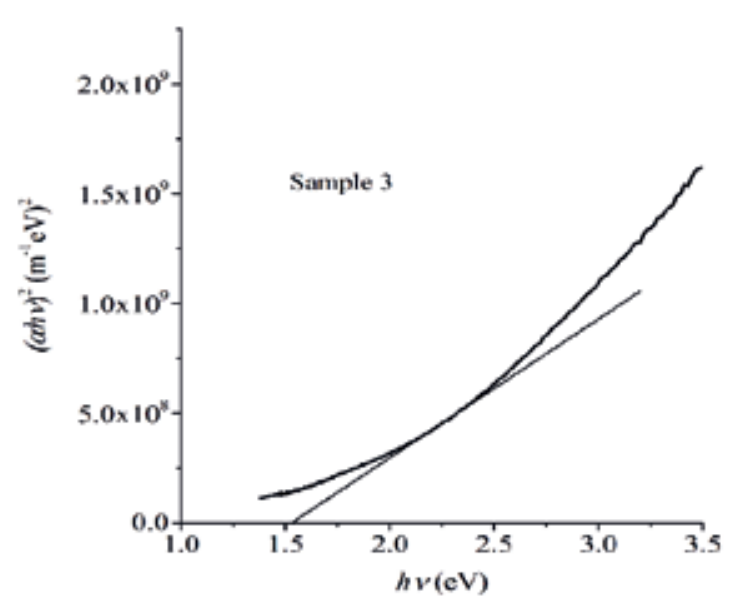

Fig. 7(c). Tauc plot-Sample 3

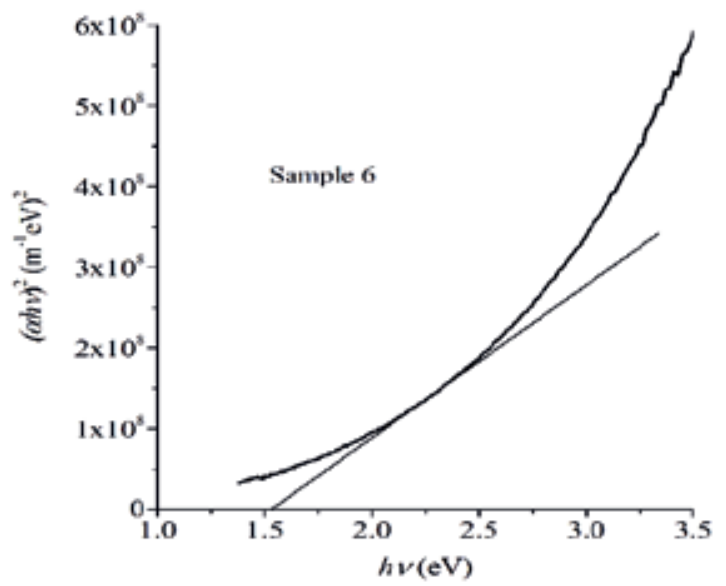

Fig. 8(c). Tauc plot-Sample 6

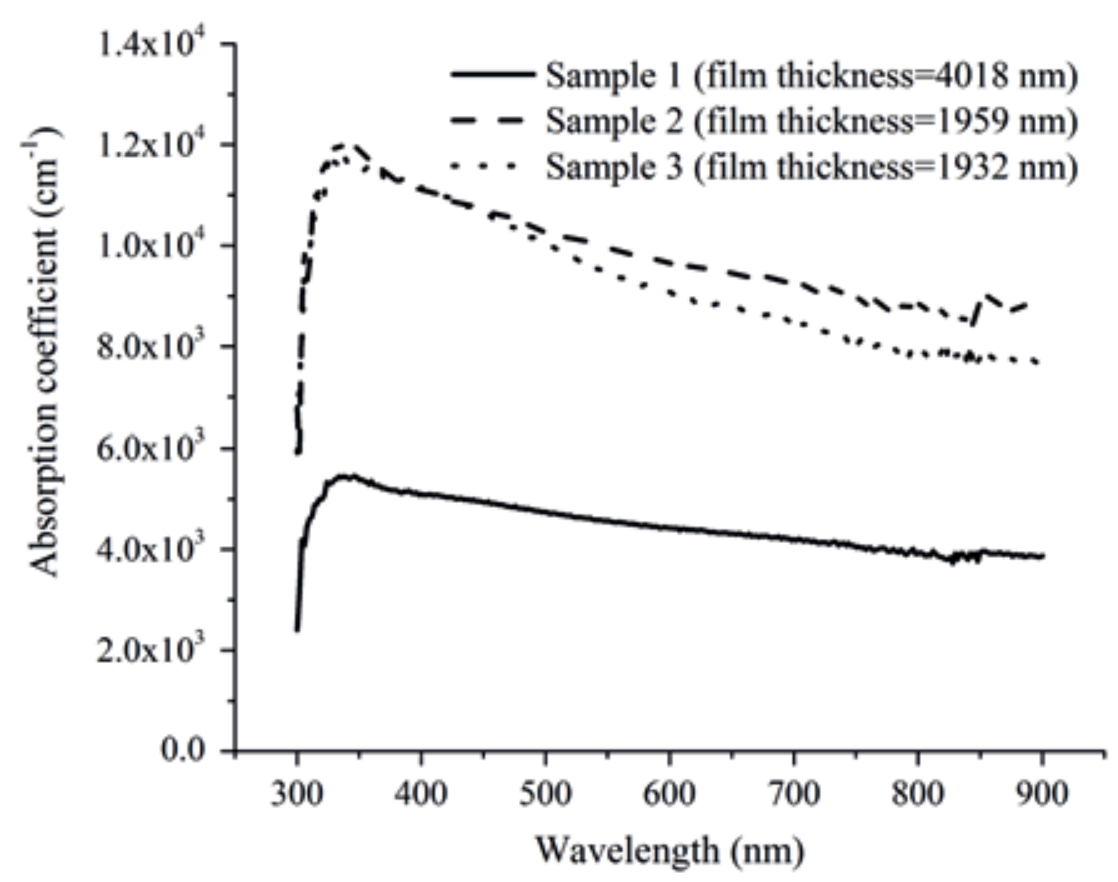

Fig. 9. Absorption coefficient vs wavelength graph of $\mathrm{N}_{2}$ gas annealed CZTS thin films

\section{Conclusion}

CZTS thin film was successfully deposited by sol-gel spin coating method. Annealing under two condition viz. $\mathrm{N}_{2}$ gasatmosphere and in $\mathrm{S}$ powder were performed. Our study revealed that sulphurized samples show better crystallinity with increasing pre-annealing temperature and the $\mathrm{N}_{2}$ annealed samples' XRD pattern remained unaffected with the variation of pre-annealing temperature. Overall, the samples annealed under $\mathrm{N}_{2}$ gas atmosphere showed better crystalline property than the sulphurized ones. All the thin films possess high optical absorption coefficient and optical band gap near to that of the bulk CZTS. So, the film developed could be used asan absorber layer in thin-film solar cell. 


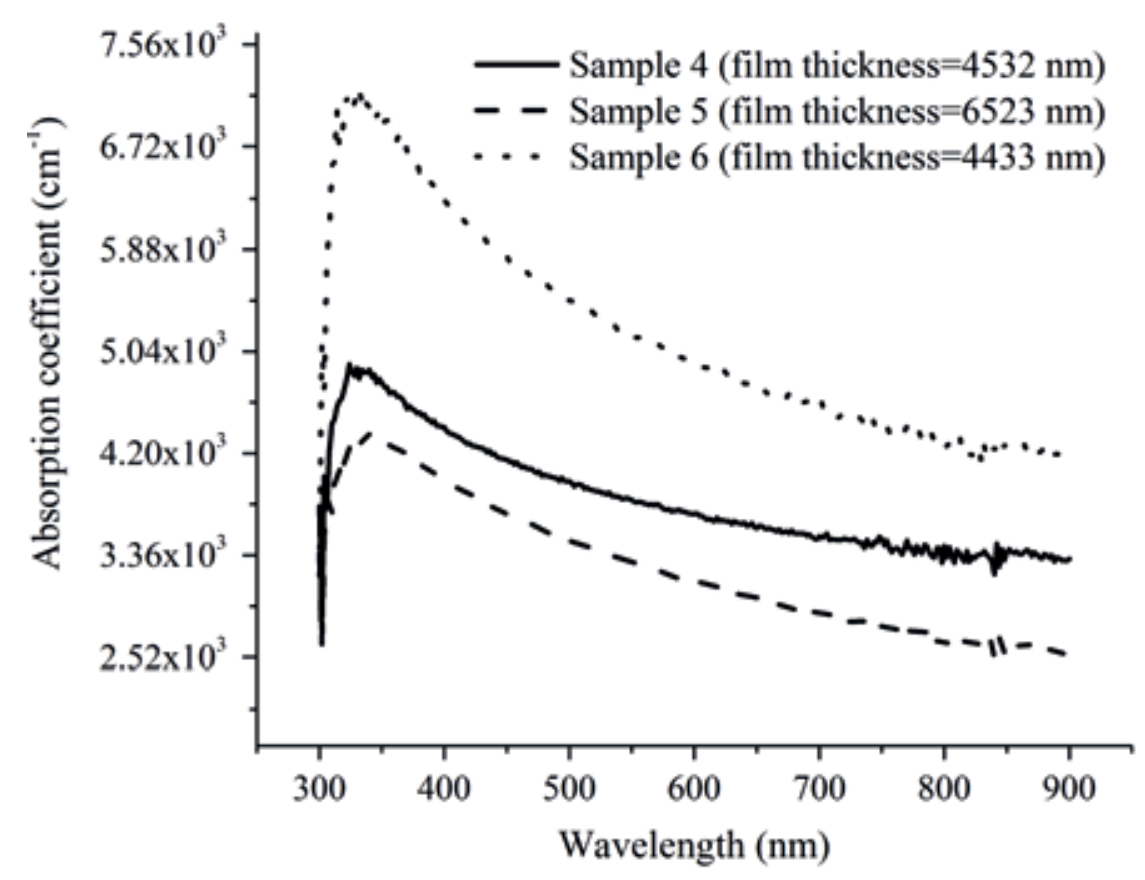

Fig. 10. Absorption coefficient vs wavelength graph of sulphurized CZTS thin films

\section{Acknowledgement}

This research work was carried out at the Institute of Fuel Research and Development (IFRD), Bangladesh Council of Scientific and Industrial Research (BCSIR), Dhaka, The People's Republic of Bangladesh.

\section{References}

Agawane G L, Shin S W, Vanalakar S A, Moholkar A V and Kim J H (2014), Next generation promising $\mathrm{Cu}_{2}\left(\mathrm{ZnxFe}_{1-} \mathrm{x}\right) \mathrm{SnS}_{4}$ photovoltaic absorber material prepared by pulsed laser deposition technique, Materials Letters 137: 147-149.

Jiang M, Fei Lan, Xingzhong Yan and Guangyong Li (2014), $\mathrm{Cu}_{2} \mathrm{ZnSn}\left(\mathrm{S}_{1-\mathrm{x}} \mathrm{Se}_{\mathrm{x}}\right)_{4}$ thin film solar cells prepared by water-based solution process, physica status solidi (RRL) - Rapid Research Letters 8(3): 223-227.

Jiang M, Yong Li, Rabin Dhakal, Prem Thapaliya, Michael Mastro, Joshua D Caldwell, Fritz Kub and Xingzhong Yan (2011), $\mathrm{Cu}_{2} \mathrm{ZnSnS}_{4}$ polycrystalline thin films with large densely packed grains prepared by sol-gel method, Journal of Photonics for Energy 1(1).
Kahraman S, Podlogar M, Bernik S, Cetinkara H A and Guder H S (2013), Effects of the sulfurization temperature on sol gel-processed $\mathrm{Cu}_{2} \mathrm{ZnSnS}_{4}$ thin, Ceramics International 39(8):9285-9292.

Li Y, Yuan T, Jiang L, Liu F, Liu Y and Lai Y (2015), $\mathrm{Cu}_{2} \mathrm{ZnSnS}_{4}$ thin film solar cell fabricated by co-electrodeposited metallic precursor, Journal of Materials Science: Materials in Electronics 26(1): 204-210.

Min Yen Yeh, Chin Cheng Lee and Dong Sing Wuu (2009), Influences of synthesizing temperatures on the properties of $\mathrm{Cu} 2 \mathrm{ZnSnS} 4$ prepared by sol-gel spin-coated deposition, Journal of Sol-Gel Science and Technology 52(1): 65-68.

Park H, Hwang Y H and Bae B (2013), Sol-gel processed $\mathrm{Cu}_{2} \mathrm{ZnSnS}_{4}$ thin films for a photovoltaic absorber layer without sulfurization, Journal of Sol-Gel Science and Technology 65(1):23-27.

Siebentritt S (2013), Why Are Kesterite Solar Cells Not 20\% Efficient?, Thin Solid Films 535: 1-4. 
Su Z, Sun K, Han Z, Cui H, Liu F, Lai Y, Li J, Hao X, Liu Y and Green M A (2014), Fabrication of $\mathrm{Cu}_{2} \mathrm{ZnSnS}_{4}$ solar cells with $5.1 \%$ efficiency via thermal decomposition and reaction using a non-toxic sol-gel route, Journal of Materials Chemistry. A: Materials for Energy and Sustainability 2(2): 500-509.

Suryawanshi M P,Patil P S, Shin S W, Gurav K V, Agawane G L, Gang M G, Kim J H and Moholkar A V (2014), The synergistic influence of anionic bath immersion time on the photoelectrochemical performance of CZTS thin films prepared by a modified SILAR sequence, RSC Advances 4(36): 18537-18540.

Tanaka T, Kawasaki D, Nishio M, Guo Q and Ogawa H (2006), Fabrication of $\mathrm{Cu}_{2} \mathrm{ZnSnS}_{4}$ thin films by co-evaporation, physica status solidi (c) $\mathbf{3}$ : 2844-2847.

Valdes M, Santoro G and Vazquez M (2014), Spray deposition of $\mathrm{Cu}_{2} \mathrm{ZnSnS}_{4}$ thin films, Journal of Alloys and Compounds 585: 776-782.
Wang J, Li S, Cai J, Shen B, Ren Y and Qin G (2013), $\mathrm{Cu}_{2} \mathrm{ZnSnS}_{4}$ thin films: Facile and cost-effective preparation by RF-magnetron sputtering and texture control, Journal of Alloys and Compounds 552: $418-422$.

Wangperawong A, King J S, Herron S M, Tran B P, Pangan-Okimoto K and Bent S F (2011), Aqueous bath process for deposition of $\mathrm{Cu}_{2} \mathrm{ZnSnS}_{4}$ photovoltaic absorbers, Thin Solid Films 519(8): 2488-2492.

Zhou S, Tan R, Jiang X, Shen X, Xu W and Song W (2013), Growth of CZTS thin films by sulfurization of sputtered single-layered $\mathrm{Cu}-\mathrm{Zn}-\mathrm{Sn}$ metallic precursors from an alloy target, Journal of Materials Science: Materials in Electronics 24(12): 4958-4963. 